\title{
Em Busca de uma Teoria da Burocracia Pública Não-Estatal: Política e Administração no Terceiro Setor
}

\author{
Humberto Falcão Martins
}

\begin{abstract}
RESUMO
O objetivo do artigo é explorar elementos que permitam a construção de uma base teórica acerca da burocracia pública não-estatal - organizações do terceiro setor voltadas à produção nãolucrativa de bens públicos, alegadamente insuscetíveis às disfunções da burocracia estatal. Esta exploração se baseia em três pontos: a) uma proposição conceitual acerca de disfuncionalidades organizacionais e políticas da burocracia estatal, que geram inefetividade, patrimonialismo e insulamento burocrático; b) uma análise comparativa sobre a possibilidade de sua ocorrência no contexto da burocracia não-estatal; e c) a identificação de requisitos de efetividade burocrática estatal e não-estatal no contexto da governança contemporânea, tais como inserção social e regulação política. Propõe-se que a burocracia pública não-estatal é relativamente mais apta ao atendimento do requisito da inserção social e menos apta ao atendimento do requisito da regulação política em bases universais. Argumenta-se que esta condição recomenda, em alguns casos, uma regulação política sobre suas ações de forma integrada ao Estado. Sustenta-se que o controle da sociedade política não é, per se, condição ou atributo suficiente para se assegurar a minimização de disfunções no âmbito da organização burocrática pública não-estatal.
\end{abstract}

Palavras-chaves: burocracia; organizações não-governamentais; disfunções burocráticas; controle político; controle social.

\begin{abstract}
The article aims at exploring some elements so as to provide a theoretical framework concerning the non-state public bureaucracy - the so called non profit NGOs which operates in the public sphere and are allegedly not prone to state bureaucracies' dysfunctions. The author follows a three step methodology: a) concept building on state bureaucracies' dysfunctions related to political and other organizational issues which underlies ineffectiveness, patrimonial action and bureaucratic insulation; b) comparative analysis on whether such dysfunctions are more or less supposed to occur in non-state bureaucracies; and c) formulation of contemporary state and non-state bureaucratic effectiveness' requisites such as social embeddedness and political regulation. I suggest that non-state bureaucracy is more prone to achieve social embeddedness while less prone to be politically regulated in an universal basis. I argue that this condition requires in some cases a kind of political regulation integrated to the state once the control that flows from the political society is not by itself enough to make non-state bureaucracies dysfunctions safe.
\end{abstract}

Key words: bureaucracy; NGOs; bureaucratic; dysfunctions; political control; social control. 


\section{INTRODUÇÃO}

Este ensaio teórico procura explorar conceitualmente um universo em formação: as organizações do denominado terceiro setor. Estas têm sido proclamadas como o advento de uma era pós-burocrática, na qual as mazelas da burocracia estatal seriam, por fim, equacionadas com maior racionalidade no seio da própria sociedade. Esta modalidade de iniciativa social busca padrões cada vez mais complexos de organização e gera profundas repercussões no cenário global da governança contemporânea.

Os cinco tópicos que seguem visam a explorar elementos que permitam a construção de uma base teórica acerca da burocracia pública não-estatal, tomando como questão central sua capacidade em resolver os problemas clássicos colocados pela burocracia pública estatal. O primeiro tópico visa a contextualizar, introdutoriamente, o movimento em direção ao terceiro setor e propor, em termos genéricos, o conceito de burocracia pública não-estatal. O segundo visa a explorar o problema organizacional da burocracia, procurando estabelecer uma comparação entre os problemas organizacionais da burocracia estatal e os da não-estatal. $O$ terceiro tópico propõe uma interpretação do problema político da burocracia e explora sua extensão, se diferenciada ou não, nas burocracias estatal e não-estatal. O quarto tópico busca identificar requisitos de efetividade burocrática no contexto da governança contemporânea e situar a ação burocrática estatal e não-estatal em face dos requisitos de efetividade. $\mathrm{O}$ quinto tópico propõe uma reflexão sobre a utopia pós-burocrática, coloca questionamentos críticos em relação à pretensão e às motivações da proposta burocrática não-estatal enquanto solução para a crise da administração pública.

\section{O Movimento em Direçāo ao Terceiro Setor}

O terceiro setor é genericamente definido como o setor de serviços não orientado para o lucro. Compreende uma diversidade de instituições tais como entidades filantrópicas, movimentos populares e sociais, associações profissionais, entidades religiosas e organizações não-governamentais de um modo geral (Fernandes, 1994). Dentro da lógica alternativa à do lucro, o terceiro setor é formado por agentes privados orientados para o interesse público, cujo atendimento via produção de bens e serviços não se destina a gerar patrimônio particular. Do ponto de vista econômico, o terceiro setor se caracteriza pela produção não-lucrativa de bens e serviços públicos, entendidos como de consumo tipicamente coletivo.

O terceiro setor é um universo institucional em expansão e consolidação. Por 
um lado, representa a consagração da evolução institucional da sociedade capitalista democrática, que tende a conferir ao associativismo um papel cada vez mais relevante na definição de novos padrões de representação de interesses nas relações Estado sociedade em geral e na formulação e implementação de políticas sociais, em particular.

Por outro lado, a consolidação do terceiro setor enquanto espaço institucional está complementarmente associada, enquanto causa e conseqüência, às transformações institucionais ocorridas no seio do Estado contemporâneo. O que se convencionou chamar de crise do Estado abrange, numa multiplicidade de enfoques, aspectos endógenos e exógenos à estrutura do Estado. Dentre os aspectos endógenos estão os atributos do aparelho e das instituições do Estado, freqüentemente associados à ineficiência: crise do welfare state keynesiano, pelas disfunções e desvantagens da intervenção estatal na garantia do bem-estar ou da estabilidade econômica, relativamente aos atributos do mercado, conforme defendido pelas correntes de inclinação neoliberal a partir dos anos 70; disfunções burocráticas ou crise do modo de implementação estatal de serviços públicos; e, dentre outras, ingovernabilidade: sobrecarga fiscal, excesso de demandas e crise de legitimidade. Dentre os aspectos exógenos, a caracterização padrão da crise do Estado engloba alguns pontos recorrentes que se interrelacionam em diferentes medidas: fim do desenvolvimentismo pós-guerra, pelo fim de Bretton Woods, as crises do petróleo, as crises de liqüidez e a instabilidade do mercado financeiro internacional, os novos requisitos de integração competitiva da globalização etc. Uma interpretação contingencialista da crise do Estado social sugere, grosso modo, a existência de ambiente social mutante, que impõe novas necessidades e novas formas de satisfazê-las, em função do qual se empreende um esforço de adaptação interativa.

Como resposta, uma das características marcantes dos processos (induzidos ou não) de reforma do Estado na atualidade tem-se caracterizado por três categorias de esforços: de racionalização, visando a otimizar a gestão pública; de descentralização, visando a aproximar gestão de serviços aos beneficiários; e de autonomização, visando a estimular parcerias baseadas no caráter público nãoestatal (Draibe, 1993). Este conjunto de iniciativas tem sido reconhecido pelas críticas conservadoras e progressistas à crise do Estado como genericamente válidas e essenciais para o estabelecimento de uma ordem administrativa mais adequada aos imperativos de democracia e eficiência (Draibe e Henrique, 1994).

Parte indissociável deste quadro é o movimento de migração da produção de políticas públicas do Estado em direção a organizações públicas não estatais pertencentes ao terceiro setor mediante processos de desestatização baseados na descentralização de serviços. Esta resposta é estimulada pela migração da esfera 
pública para uma zona intermediária entre Estado e sociedade. O movimento em direção ao terceiro setor representa, sobretudo, uma mudança estrutural na esfera pública, outrora domínio exclusivo dos cidadãos, da burguesia e, sucessivamente, do aparelho de proteção social estatal.

As mudanças no caráter da esfera pública representam uma trajetória de desintegração da esfera pública burguesa pelo Estado social e deste pela sua crise. $\mathrm{Na}$ dimensão política, a consolidação de uma nova esfera pública representa a substituição do poder político pelo poder social, na qual a preservação da atividade política depende da mediação de organizações da sociedade, não do Estado. Com efeito, as iniciativas civis no domínio do terceiro setor têm características de autonomia em face do poder público. A consolidação do terceiro setor representa uma nova etapa da divisão do trabalho burocrático entre Estado e sociedade (Ribeiro, 1997).

Como marco conceitual, esta nova etapa da divisão do trabalho burocrático caracteriza-se pela existência de uma forma híbrida de organização pública: a burocracia pública não-estatal. Por analogia conceitual, trata-se de um sistema organizacional fundado na racionalidade instrumental-impessoal que se insere num contexto específico de espaço institucional e poder no terceiro setor: a produção de bens públicos. Há abundante evidência empírica de que as organizações atuantes no terceiro setor buscam desenvolver formas organizacionais mais sistematicamente compatíveis com a crescente importância de suas ações (Mendes, 1997). A burocracia pública não-estatal é forma e expressão do poder social: compete por legitimidade, espaço e influência. Do ponto de vista da gestão, a burocracia pública não-estatal tende a apresentar características híbridas entre uma estrutura organizacional e um modelo de gestão estatal — como instâncias deliberativas colegiadas - e outro tipicamente privado — como os processos, principalmente os de apoio.

O terceiro setor, de um modo geral, e a burocracia pública não-estatal, em particular, têm sido proclamados como o advento de uma era pós-burocrática, na qual as mazelas do Estado seriam equacionadas com maior racionalidade e legitimidade no seio da própria sociedade. Esta expectativa não se aplica apenas à superioridade das formas organizacionais envolvidas na produção de bens públicos, mas, sobretudo, à sua dinâmica de controle social. Os próximos tópicos visam a explorar o espaço conceitual da burocracia pública não-estatal, propondo questões sobre a sua capacidade em resolver os problemas clássicos colocados pela burocracia pública estatal ao longo dos últimos cem anos. 


\section{Sobre o Problema 'Organizacional' da Burocracia}

Os problemas organizacionais ${ }^{(1)}$ da burocracia situam-se em torno da busca pela eficiência e pela efetividade. Resumidamente, trata-se da sua capacidade operacional em maximizar resultados, minimizar recursos e orientar-se finalisticamente para resultados úteis, em conformidade qualitativa e quantitativa com as necessidades dos beneficiários de sua ação. Este problema se reporta à busca de estruturas organizacionais e modelos de gestão que assegurem o alcance de padrões de eficiência operacional e satisfação compatível com a expectativa de atores que influenciam a definição da missão institucional da organização burocrática - cidadãos, políticos, os próprios burocratas etc. A diferença básica entre a burocracia pública estatal e a não-estatal reside no fato de que a última dispõe de grau de autonomia bastante maior para definir beneficiários - segmento-alvo -, produtos e meios, enquanto no caso da primeira a definição dos segmentos beneficiários ampara-se numa disposição legal, assim como a escolha dos meios está sujeita às regras da administração estatal.

Uma derivação deste problema é que o consagrado tratamento dado ao problema organizacional da burocracia origina-se na clássica formulação de Max Weber, que enalteceu a superioridade técnica da burocracia e estampou sua feição organizacional no tipo-ideal burocrático. Esta tradição, difundida no campo das ciências sociais aplicadas, que lidam com a busca de soluções para o problema organizacional da burocracia, assenta-se numa falha de natureza epistemológica, que obscurece um enunciamento do problema organizacional da burocracia menos restrito à morfologia idealtípica weberiana e mais centrado na sua natureza política. A apreciação do problema organizacional da burocracia pode apenas raramente contar com uma abordagem condizente com a complexidade e perspectiva da sociologia política de Weber. Isto se reflete, grosso modo, em duas perspectivas: a da sociologia das organizações e a da administração.

Na perspectiva da sociologia das organizações estão aqueles que fizeram uma leitura predominantemente - em alguns casos, exclusivamente — organizacional da relação de disfuncionalidade entre organização burocrática (seus atributos morfológicos) e fenômeno burocrático (burocracia enquanto forma de dominação racional-legal). Dentre estes estão, principalmente, Merton (1959), que explora na morfologia burocrática típica uma tendência ao deslocamento de objetivos em direção a regras, normas e interesses próprios; Michels (1949), que identifica uma tendência à oligarquização segregatória do poder intraburocrático; Von Mises (1944), que explora o caráter anti-inovador, reforçador do status quo, da estrutura burocrática; Selznick (1964), que denuncia o paradoxo da organização burocrática, ou as influências da organização informal em torno de seus objetivos 
próprios; Gouldner (1954), que identifica uma relação entre mecanismos de supervisão e controle e uma tendência à acomodação em torno de padrões mínimos; e Crozier (1979), que desmascara o círculo vicioso da burocracia, sua incapacidade estrutural em corrigir-se de forma sistêmica, ancorando-se em estratégias conservadoras e formalistas de autoproteção. O problema comum destas perspectivas é que se baseiam na presunção de que existe um tipo burocrático, um modelo típico de organização burocrática; aceitam como válido o modelo utilizado por Weber, não raro tomado como proposição normativa; e direcionam sua crítica à inviabilidade organizacional deste modelo típico, tendenciosamente autoorientado.

Na perspectiva da administração estão os autores que delimitam uma escola weberiana no pensamento administrativo, inferem suas prescrições administrativas e, enfim, qualificam sua contribuição para o campo da administração. Assim, para Kast e Rosenweig (1970), Weber forma, ao lado de Taylor e Fayol, o terceiro pilar da escola clássica da administração; Etzioni (1976) o considera um precursor da escola estruturalista; March e Simon (1967) incluem Weber no rol dos arquitetos da organização formal, no qual figuram os anatomistas clássicos como Gullick e Urwick - apesar de reconhecerem que a burocracia comporta diferentes níveis de análise-; e Blau e Scott (1970) consideram Weber um precursor da escola clássica, notadamente do princípio do one best way (o modelo burocrático) para a eficiência. Muitos teóricos da administração ainda consideram Weber, com poucas variações, o pai da burocracia (sic).

Estas duas perspectivas têm dois traços em comum: uma sistemática incompreensão da burocracia no contexto da sociologia política de Weber e uma confusão acerca dos atributos epistemológicos dos tipos-ideais. O primeiro traço resulta numa compreensão organizacional de burocracia, desconectada de uma visão da burocracia em Weber, no conjunto de sua obra. Falham os sociólogos e administradores ao tentar conceituar a burocracia a partir da organização burocrática, porque "antes de mais nada, burocracia é poder" (Bresser Pereira e Prestes Motta, 1980).

O segundo traço apóia-se na confusão entre organização burocrática e o idealtipo descrito por Weber, que de recurso puramente metodológico, no qual não cabe identificação com a realidade (Freund, 1975), é transformado em modelo prescritivo (Bertero, 1981). Parsons (1937), aliás, demonstra seu descontentamento com o termo, ao afirmar que a organização burocrática descrita no idealtipo não tem nada de ideal: se fosse ideal não seria tipo, porque estes derivam da realidade empírica; se fossem tipos não seriam ideais, porque estes derivam da pura abstração. O idealtipo burocrático é, aliás, dos mais pobres utilizados por Weber: seus elementos podiam ser encontrados na ciência da administração alemã de então. A validade epistemológica deste recurso, largamente utilizado por Weber em outras 
abordagens, não está em questão, senão sua utilização para a compreensão do fenômeno burocrático.

A armadilha epistemológica — da qual Weber é, até hoje, vítima— que captura, no domínio das ciências sociais aplicadas, a apreciação do problema organizacional da burocracia, oculta o fato de que a burocracia, enquanto fenômeno de poder, prescinde de uma organização burocrática típica. Dito de outra forma, não há organização burocrática típica, senão aquela que se baseia, de uma forma bastante flexível no que se refere à sua morfologia, num sistema formalimpessoal centrado na racionalidade instrumental.

Em contrapartida, a organização pós-burocrática tem sido colocada como promessa de felicidade organizacional, de libertação dos efeitos da burocracia sobre pessoas e sociedade, porque sua formatação organizacional seria ou poderia ser diferente da aludida por Weber. Warren Bennis (1973) está entre os precursores desta idéia já em 1966 na sua obra Changing Organizations, reeditada em 1973 sob o título de Beyond Bureaucracy. A idéia, invariavelmente baseada no mesmo argumento, fez escola: Mosher (1971), Toffler (1980) e Drucker (1985) aprimoraram-na, nesta perspectiva, ressaltando a necessidade de organizações mais flexíveis, mais temporais - adhocracia —, mais adequadas à dinâmica ambiental de incerteza e turbulências relacionadas a mercados —novas necessidades-, tecnologias - novas formas de satisfazê-las-, e à ecologia humana. De uma forma geral, esta perspectiva contingencialista está na base da imensa maioria de enfoques contempoorâneos de otimização, intervenção e gestão organizacional do Desenvolvimento Organizacional à Gestão da Qualidade Total, à Reengenharia etc.

A tradição organizacional pós-burocrática se baseou no falso pressuposto de que o problema da burocracia era exclusivamente organizacional:

"Alguns autores restringem o conceito de burocracia a um tipo de sistema social rígido, centralizado, que se amolda quase perfeitamente ao tipo ideal de burocracia descrito por Max Weber. Para esses autores bastaria que o sistema social se afastasse um pouco desse modelo, que se descentralizasse, que se flexibilizasse para deixar de ser uma organização burocrática [...] Todo sistema social administrado segundo critérios racionais e hierárquicos é uma organização burocrática. Haverá organizações burocráticas mais flexíveis ou mais rígidas, mais formalizadas ou menos, mais ou menos autoritárias [...] Assim, a crítica administrativa, ao afirmar as fontes de ineficiência da organização burocrática, ou ao afirmar que estamos passando para uma fase de organizações pós-burocráticas, na verdade, legitima ideologicamente a burocracia, enquanto poder e dominação que é" (Bresser Pereira e Prestes Motta, 1980, p. 12-13, p. 224). 
Por certo que o problema organizacional da burocracia subsiste inobstante sua dimensão epistemológica —o indevido tratamento weberiano nas ciências sociais aplicadas. O ponto a reter é que o problema organizacional da burocracia tem constituído um desafio plenamente transponível. Por um lado, é inegável a modernização organizacional da burocracia em face dos imperativos de funcionalidade decorrentes da sociedade contemporânea. $\mathrm{O}$ efeito de novas demandas, qualitativas e quantitativas, e novas ofertas - tecnológicas, principalmente - tem logrado um acentuado redesenho da organização burocrática, por vezes abrupto, radical, virtualizado.

Em síntese, o problema organizacional da burocracia é relativamente fácil de ser equacionado: há bastante tecnologia gerencial disponível e em criação para se assegurar a constante modernização organizacional dos sistemas burocráticos. Há uma verdadeira indústria da modernização organizacional da burocracia, agitada pelas constantes ameaças competitivas, mesmo fora do apelo das panacéias de época.

Certamente a burocracia estatal apresenta maior dificuldade estrutural em empreender processos de modernização organizacional. A burocracia pública nãoestatal é, em contrapartida, organizacionalmente superior pelo simples fato de ser mais flexível à modernização organizacional. A diferença entre ambas no que toca à capacidade de se modernizar organizacionalmente pode atingir níveis notáveis, mas o fato é que ambas são modernizáveis organizacionalmente. $O$ ponto que concerne é a extensão na qual a otimização organizacional da burocracia se coaduna com a resolução ou atenuação do seu problema político.

\section{Uma Interpretação do Problema Político da Burocracia}

O problema central da burocracia, segundo Weber, não é organizacional, mas político. Max Weber não fez teoria das organizações numa ótica organizacional, mas contribuiu para seu desenvolvimento na perspectiva de sua sociologia política. $\mathrm{O}$ destaque da abordagem weberiana sobre a burocracia não está na descrição das suas características organizacionais, mas como a abordagem se coloca no seu quadro de pensamento social (Wrong, 1970).

Weber foi pioneiro no apontar a problemática da desintegração entre política e administração na perspectiva do Estado moderno. Segundo seu argumento, o surgimento do Estado burocrático implicaria a renúncia de responsabilidade pela liderança política e na usurpação das funções políticas por parte dos administradores. A questão por detrás desta problemática é o contraste, a distinção e a 
tensão entre a racionalidade substantiva da busca de interesses e a racionalidade instrumental-formal do exercício da autoridade.

"O progresso da burocratização dentro da própria administração estatal é um fenômeno paralelo ao desenvolvimento da democracia [...] É certamente necessário ter sempre em mente que a expressão 'democratização' pode ser enganosa. O próprio demos, no sentido de uma massa amorfa, jamais 'governa' associações maiores; mas, ao invés disso, é governada. O que muda é apenas a forma pela qual os líderes do executivo são selecionados e a medida de influência que o demos, ou melhor, que os círculos sociais em seu meio, podem exercer sobre o conteúdo e direção das atividades administrativas [...] 'Democratização', no sentido aqui pretendido, não significa necessariamente uma participação cada vez mais ativa dos governados na autoridade da estrutura social. Isso pode ser um resultado da democratização, mas não é necessariamente o caso [...] A expressão, geralmente imprecisa, 'democratização' não pode ser usada aqui, na medida em que é entendida como a minimização da capacidade governativa do funcionário público em favor do maior domínio 'direto' possível do demos, que na prática significa os respectivos líderes partidários de demos. $\mathrm{O}$ aspecto decisivo senão exclusivo - no caso é o nivelamento dos governados em oposição ao grupo dominante e burocraticamente articulado, que por sua vez pode ocupar uma posição bastante autocrática, tanto de fato quanto na forma [...] Daí ter esse processo significado um progresso da burocracia e, ao mesmo tempo, da democratização 'passiva' [...]" (Weber, 1978, p. 984986).

A democracia de massas impõe, ao contrário da democracia direta, que os governados influenciem as decisões executivas de seus governantes por meio da representação política. Fundamentalmente, a sociologia política de Weber põe em evidência os riscos da desintegração entre política e administração, processo de inversão da racionalidade burocrática, cuja tendência ao absolutismo burocrático ameaça a legitimidade do Estado. Weber não propõe uma teoria funcional da integração entre política e administração. No nível político, sua sociologia política aceita o conflito entre política e administração, razão substantiva e instrumental, fatos e valores, como insolúvel, embora passível de equilíbrio mediante o exercício efetivo da liderança política.

Mas o núcleo do problema da dicotomização entre política e administração é que o que inicialmente parecia ser uma necessidade decorrente da escala, complexidade e especificidade institucional — da democracia de massas — da função legislativa, transformou-se em integração disfuncional entre política e administração, à medida que se tornou imperativo de conveniências da burocracia enquanto expressão de poder organizacional. A dicotomia entre política e adminis- 
tração é atributo da divisão social do trabalho burocrático no contexto do Estado moderno; a integração disfuncional é decorrência desta divisão, à medida que a burocracia chama para si o próprio trabalho político.

"Esse [...] problema parecia ser o maior aos olhos de Weber [:] sob a dominação legal, o exercício diário da autoridade fica nas mãos da burocracia. Mesmo o sucesso na disputa por votos, em debates parlamentares e nas eleições legislativas pode resultar em nada se não for acompanhado de um controle efetivo sobre a implementação administrativa. Quando não se consegue tal controle, a burocracia usurpa o processo de decisão política de acordo com sua tendência fundamental [...] de transformar todos os problemas políticos em problemas administrativos" (Bendix, 1986, p. 338; Manheim, 1949, p.105).

A despeito de sua morfologia organizacional, apenas incidentalmente é a burocracia em Weber compreendida no seu significado sociológico original, segundo o qual figura como forma moderna de dicotomização ou integração disfuncional entre política e administração, pelo isolamento da administração em relação às premissas valorativas da ação pública ou pelo seu reverso, a usurpação, pela administração, das funções políticas. A extensão do problema político da burocracia está nas formas de integração ou dicotomização entre política e administração, se mais ou menos funcionais no cenário da governança. Esta questão se relaciona, certamente, às formas organizacionais da burocracia, mas não está restrita ao seu domínio.

O problema político da burocracia estatal é crítico no seio do Estado. A dicotomia entre burocracia estatal e sistema político pode assumir formas que variam do insulamento burocrático, da burocracia em relação ao sistema político, à captura clientelista predatória da política ou do sistema político em relação à burocracia. Nestes mesmos casos extremos cabem também situações de integração disfuncional, tais como alianças espúrias entre segmentos políticos e burocráticos em busca de rendas patrimoniais decorrentes de privilégios, proteção ou corrupção — a própria noção de estamento burocrático, conforme proposta por Faoro (1984), insere-se nesta perspectiva.

A burocracia pública não-estatal está sujeita à mesma categoria de problemas, mas de formas distintas. Por definição, esta não se sujeita ao controle finalístico direto do sistema político, mas se insere na categoria de controle social: dispõe de autonomia, salvo se conveniada do Estado, para definir seus segmentos beneficiários e identificar suas necessidades. Em primeiro lugar, está claro que o alcance do controle social não se refere à sociedade em geral, mas ao segmento de beneficiários-alvo e representantes setoriais, do ramo de atuação. Trata-se, portanto, de um controle micro-social, setorizado —embora seja possível o alarga- 
mento do âmbito de controle social ao largo do sistema político via mecanismos de representação mais amplos.

Ainda que o controle social seja exercido com eficiência, este não imuniza o insulamento ou a captura, mas, dependendo da eficácia da representatividade dos mecanismos de controle social, pode reduzir seu risco de ocorrência. O que subjaz a esta questão é a nem sempre clara relação de complementaridade entre controle social e controle político. O controle social proporciona um controle político no nível micro-social; não no âmbito da sociedade política, que não se dissocia do Estado, uma vez que apenas este proporciona a representação político-intitucional. O controle social complementa, mas não substitui o controle político, porque é uma expressão segmentada da sociedade política.

Ademais, é necessário relembrar que a própria consolidação do terceiro setor repousa numa iniciativa de substituição do poder político pelo poder social. Nesse sentido, a burocracia pública não-estatal constitui, por um lado, uma estratégia de dicotomização entre a sociedade política e a administração dos bens públicos demandados pela sociedade, à medida que procura tornar-se autônoma do Estado. A burocracia pública não-estatal sujeita-se, embora em menor grau e abrangência, às disfuncionalidades políticas da burocracia pública estatal.

\section{Burocracia Estatal e Burocracia Não-Estatal no Contexto da Governança Contemporânea}

O cenário da governança ${ }^{(2)}$ contemporânea se caracteriza por uma espécie de influência burocrática sobre a prática política e de influência política sobre a prática burocrática, conforme sugerida por Aberbach, Putnam e Rockman (1981), ao descrever um processo de politização da administração e burocratização da política como a consagração de um padrão de relações entre políticos e burocratas nas poliarquias contemporâneas. O processo de politização da administração sugere um progressivo movimento de autonomia burocrática, até mesmo para manter canais de representação de interesses com segmentos da sociedade, independentemente do sistema político. O processo de burocratização da administração sugere um esforço crescentemente sistemático de regulação política tanto da burocracia quanto de segmentos da sociedade. Inserção social da burocracia estatal e regulação política sobre a burocracia estatal tornam-se requisitos de efetiva governança.

O aspecto mais relevante da integração entre política e administração é a necessária relação de funcionalidade recíproca entre inserção e regulação. A regulação 
política sobre a burocracia é um empecilho à sua tendência de auto-orientação. A inserção social, mediante a orientação para o usuário, é uma forma de equilíbrio necessária à regulação não apenas da burocracia, mas da política e de sua influência sobre a burocracia. Numa condição de equilíbrio burocrático, de integração entre política e administração, ambas são indissociáveis. O Diagrama 1 ensaia, num único quadro de referência, os dois continua de análise da burocracia no contexto da governança contemporânea: por um lado, a burocratização da política e a politização da administração e, por outro, os requisitos de inserção e regulação:

\section{Diagrama 1: Integração Política-Administração: Autonomia Regulada e Inserida}

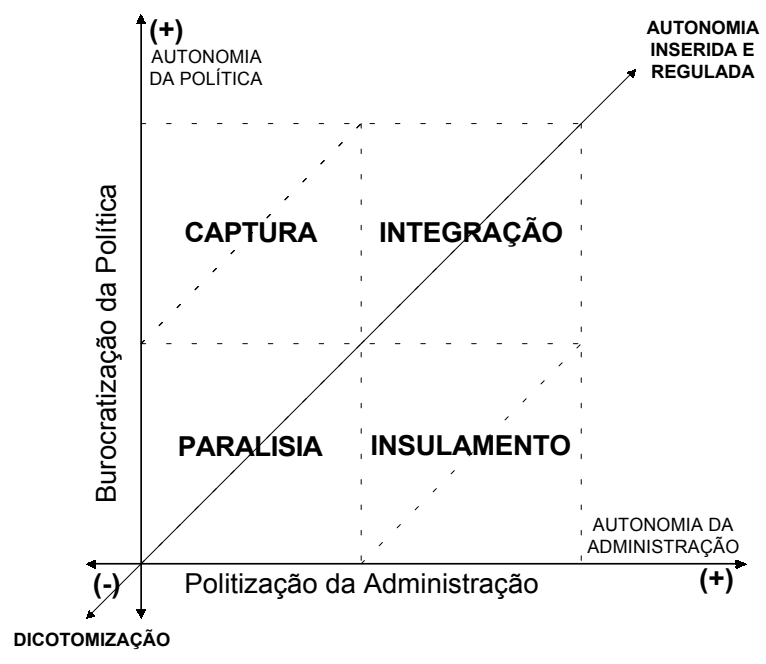

Os quadrantes representam formas típicas de integração/dicotomização entre política e administração. Os eixos representam pólos tendenciais. No quadrante integração caberiam, por exemplo, dois tipos de integração entre política e administração: um de integração competitiva, caso típico da poliarquia presidencialista norte-americana, em que o congresso compete com a administração e a influencia; outro de integração cooperativa, caso das poliarquias parlamentaristas européias, em que a administração é formada de dentro do parlamento. O mesmo eixo comporta, conforme o esquema, no sentido descendente, duas situações típicas de desintegração: captura, situação de pouca autonomia burocrática e excessiva regulação política, padrão tipicamente clientelista; e insulamento, situação de excessiva autonomia burocrática e baixa regulação política, que pode resultar em 
auto-orientação ou alianças espúrias do tipo anéis burocráticos. O quadrante esquerdo inferior representa uma situação de paralisia, na qual a ação burocrática perde autonomia, não se insere e não está politicamente regulada.

A dicotomização entre política e administração é um problema político central da burocracia. O problema da dicotomização entre política e administração no contexto da governança contemporânea é que as formas burocráticas estatal e não-estatal engendradas na sua operação não asseguram o desenvolvimento de adequados recursos organizacionais e institucionais de inserção e regulação política concomitantes. Com efeito, boa parte das buropatologias vislumbradas pelos sociólogos das organizações — no sentido das disfunções oriundas da "excessiva burocratização" (Caiden, 1994) — estavam referidas à não regulação política ou à não inserção social. Outro problema é que estas buropatologias estão localizadas mais fora do que dentro das organizações burocáticas, não em decorrência exclusiva da sua formatação organizacional, mas da forma pela qual se relaciona com seu meio externo no contexto da governança. É à luz deste requisito que suas formas organizacionais devem ser analisadas.

A integração disfuncional entre política e administração verifica-se, primeiro, porque a prática da política burocrática não repousa exclusivamente nos atributos estruturais da mecânica democrático-representativa, senão da crescente predominância decisória da burocracia inserida neste contexto (Lindbloom, 1980). Segundo, porque tampouco a politização da administração é o resultado de novos critérios de relevância assimilados e processados pela burocracia pública, conforme um padrão de racionalidade prática e valorativa, mas o resultado de um processo em que a ação estatal típica do Estado de direito, condicionada aos seus processos e imperativos racionais-legais, torna-se crescentemente inconfiável(Offe, 1984). É em parte em função deste quadro que a burocracia do terceiro setor se consolida, de modo a rever as bases de sustentação da política burocrática, mediante maior participação e controle social, assim como a expressão da politização de uma administração pública não-estatal segundo padrões definidos de racionalidade prática e valorativa — que vão desde vinculações partidárias à defesa de causas específicas. O poder público estatal compete ou coopera com o poder público não-estatal pela legitimidade da representação dos interesses da sociedade e pelo suprimento de bens públicos necessários ao atendimento de necessidades sociais.

Política e administração — por um lado, sistema político-representativo e agências de governo; por outro, segmentos sociais e agências não governamentais, enquanto arenas institucionais - integram-se ou dicotomizam-se de diferentes formas à medida que competem ou cooperam tanto na identificação e agregação de interesses da sociedade civil, quanto na formulação e implementação das políticas públicas. O Diagrama 2 procura ilustrar esse quadro. 


\section{Diagrama 2: Estado e $3^{\circ}$ Setor no Contexto da Governança Contemporânea}

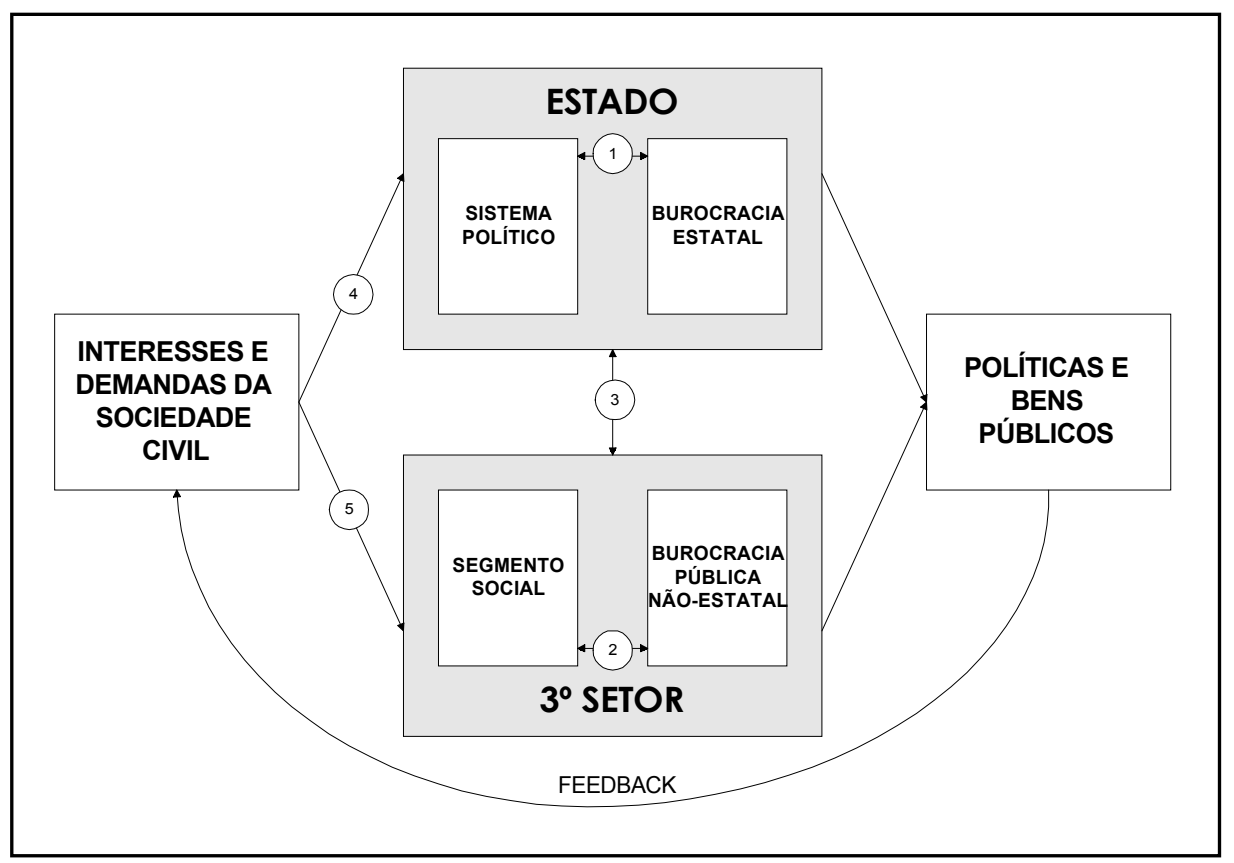

A questão, conforme se apresenta, é, em ambos os casos — Estado e terceiro setor - estabelecer um padrão de interação entre política e administração que atenda simultaneamente aos requisitos de inserção social e regulação política para o alcance de níveis de autonomia relativa, que são negociados nas relações contratuais — de delegação ou representação de interesses - entre os principais atores da ação pública. Esta visão sistêmica tanto da governança, quanto, inserida no seu contexto, da integração entre política e administração, pode ser mais bem qualificada utilizando-se como referência a abordagem do agente $\mathbf{x}$ principal.

Na perspectiva do modelo do agente $\mathbf{x}$ principal, as transações sociais entre atores na esfera tradicional do Estado e do mercado podem ser enfocadas a partir de uma relação tipo agente-contratado e principal-contratante (Melo, 1996). Os requisitos de inserção e regulação são tratados enquanto interdependência sistêmica de três espécies de relação: entre Estado - burocracia e sistema político - e agentes econômicos; entre políticos e burocratas; e entre cidadãos e políticos (Przeworski, 1996). Se uma quarta categoria puder ser aditada a este esquema, propõe-se uma que concerne à relação entre poder público estatal e poder público não-estatal. 
A primeira relação, entre Estado e agentes econômicos — ou sociais — pode ser, por analogia, visualizada no Diagrama 1 pelos círculos (4) e (5). A relação entre Estado e agentes da sociedade, círculo (4), pode ocorrer por meio da representação política ou por outros meios de representação de interesse que não sejam via terceiro setor. No caso da relação entre terceiro setor e agentes sociais, círculo (5), o padrão de representação de interesses se estabelece mediante algum tipo de representatividade institucional em órgãos deliberativos ou mediante alguma forma de participação direta tais como associação ou assembléia. A representação de interesses entre sociedade e terceiro setor tende a ser mais eficaz e transparente, embora mais restrita a determinados segmentos.

O segundo padrão de relação típica se estabelece, no Estado, entre políticos e burocratas, círculo (1) do Diagrama 2, e entre instâncias deliberativas representativas do segmento social beneficiário e burocracia pública não-estatal, círculo (2). Em ambos os casos pode haver maior ou menor integração — cooperação- ou desintegração - insulamento ou captura —, mas este tipo de relação no âmbito do terceiro setor tende a ser mais cooperativa, dada sua natureza mais voltada a participação e centrada no controle social.

O terceiro padrão de relação típica é firmado entre cidadãos e políticos, ou, por analogia, entre cidadãos e seus representantes nas instâncias decisórias do terceiro setor. $\mathrm{O}$ fato a ser ressaltado é que o caráter institucional da relação entre cidadãos e políticos é, na democracia contemporânea, universal. Já a relação entre cidadãos e instâncias deliberativas da burocracia pública não-estatal é restrita ao segmento social específico e estabelecida segundo normas específicas.

O quarto tipo de relação derivado da consideração clássica agente-principal estabelece-se entre poder público estatal e poder público não-estatal, representado pelo círculo (3) no Diagrama 2. Esta relação é necessariamente variada, podendo representar: regulação estatal sobre determinados segmentos da ação social; fomento estatal a determinadas ações sociais; e participação social ou representação de interesses em instâncias de deliberação estatal, via segmentos sociais atuantes no terceiro setor.

Embora essencialmente interdependentes, estas quatro categorias de relações representam vetores de um conflito por autonomia relativa entre os principais atores com os quais as burocracias estatal e não-estatal se relacionam. A própria autonomia do Estado tende a ser vista como resultante desta interação (Przeworski, 1995). Analogamente, a autonomia do terceiro setor também pode ser colocada nestes termos (Fernandes, 1994).

Esta concepção sistêmica da produção de bens sociais no contexto da governança permite visualisar com clareza a possibilidade de conflito entre inserção social e 
regulação política da ação social da burocracia estatal ou não-estatal. Trata-se da possibilidade de um alto grau de autonomia incrustada (embedded autonomy) - como a definiu Evans (1989) — do ponto de vista da capacidade governativa relacionada à implementação da ação burocrática, caracterizada por alto grau de cooperação de atores privados e com fraca supervisão política. Nesse caso, a ação burocrática, principalmente não-estatal, embora inserida, sujeita-se aos riscos de dicotomização relativamente aos objetivos políticos da sociedade como um todo. Com efeito, parte do entusiasmo que tem caracterizado a consolidação do terceiro setor decorre não apenas da maior eficiência operacional, mas em grande medida de uma causa. A sedimentação burocrática destas causas pode levar a uma espécie de (neo)insulamento burocrático não-estatal legitimado socialmente — pelo menos no âmbito do segmento.

Por outro lado, a questão da autonomia politicamente regulada mediante baixa inserção social está na base do equilíbrio dinâmico ao qual se referiu Einsenstadt (1978). Ele define o equilíbrio burocrático como uma situação na qual a burocracia, dotada de um grau mínimo de autonomia, atende ao interesse público, quando está supervisionada por legítimos titulares de poder. O que subjaz a esta visão de burocracia representativa é o requisito, exclusivo, da regulação política. $\mathrm{O}$ autor define, complementarmente, duas situações de quebra do equilíbrio da regulação burocrática: a burocratização, um ganho de autonomia pelo qual o interesse público é restrito a interesses próprios ou particularistas; e a desburocratização, uma situação típica de perda de autonomia que leva à captura do interesse público por alianças subservientes essencialmente predatórias e parasíticas firmadas entre a burocracia e segmentos externos, da sociedade civil e do sistema político. O pólo da desburocratização ilustra uma situação de inserção disfuncional, porque o que subjaz ao equilíbrio burocrático de Eisenstadt (1978) é a idéia de que a regulação política é auto-suficiente para assegurar a legitimidade dos sistemas burocráticos. Não obstante, parte do que Eisenstadt (1978) definiu como desburocratização poderia, na perspectiva da governança contemporânea, ser definida como desburocratização estatal ou burocratização não-estatal.

Em resumo, o terceiro setor pode contribuir efetivamente para assegurar maior e melhor governança, à medida que os requisitos de inserção e regulação possam ser atendidos. O que transparece da análise empreendida é que a burocracia pública não-estatal é estruturalmente menos apta ao atendimento do requisito da regulação política em bases universais. Mas esta condição não invalida e, possivelmente, reforça a necessidade de uma regulação política mais efetiva sobre as ações sociais da burocracia pública não-estatal, principalmente sobre aquelas com as quais o Estado estabelece alianças baseadas na subvenção. Em suma, o controle social, per se, não é condição ou atributo suficiente para assegurar a minimização do problema da organização burocrática pública não-estatal. 


\section{A Utopia Pós-Burocrática}

A utopia pós-burocrática é tão intrincada quanto o dilema no qual é tradicionalmente colocada a burocracia e, sobretudo, mal interpretada, no enfoque weberiano: ou se submete a burocracia ao controle político, incrementando-se o exercício da política, ou se cria uma burocracia que não seja puramente instrumental, mas integrada e permeada pela racionalidade do sistema político — regulação-e da sociedade —inserção—, não pela sua própria racionalidade —alternativa esta timidamente explorada por Weber apenas no que respeita à regulação política, $\mathrm{o}$ que lhe rendeu a pecha de pessimista e determinista.

A utopia pós-burocrática é o sentido correto de superação das disfunções burocráticas na sociedade burocrática. $\mathrm{O}$ ideal de liquidação da burocracia é o ideal de uma burocracia articulada com a racionalidade substantiva de forma funcional, $\mathrm{o}$ que no contexto da governança democrática significa inserção e regulação, quer da burocracia pública estatal, quer da não-estatal.

Por outro lado, o fatalismo burocrático - tipicamente weberiano-, ou a negação da utopia pós-burocrática, consiste em se estabelecer um continuum conceitual entre a inversão da racionalidade da ação burocrática e o processo de racionalização, de caráter histórico-mundial (Offe, 1984). A atribuição à burocracia de um pathos metafísico (Gouldner, 1964) leva à consideração da dominação burocrática como um critério estrutural irreversível para as sociedades futuras, cuja transcendência independe de uma racionalidade integrativa de inserção e regulação. Outro desdobramento do fatalismo weberiano é a conversão de qualquer forma de organização não-estatal, ou dissemelhante da descrição idealtípica, em panacéia pós-burocrática. Com efeito, a consolidação do terceiro setor tem sido, em casos relevantes, considerada panacéia para todos os males da burocracia pública estatal, principalmente porque a percepção do problema da burocracia estatal tem sido predominantemente organizacional, focada na eficiência, amparada no requisito de inserção e descuidada do requisito da regulação política. A perduração do mito da sociedade pós-burocrática varia diretamente com a ilusão da exclusividade organizacional do problema da burocracia. Por outro lado, o mito da autonomia burocrática aumenta os riscos da substituição do poder político.

Nesta perspectiva, a superação da crise da administração pública mediante uma alternativa pretensamente pós-burocrática deve extrapolar a modernização das formas burocráticas e se relacionar ao equacionamento dialético da questão, qual seja à busca de paradigmas de administração pública estatal e não-estatal que integrem a racionalidade política e a racionalidade instrumental numa racionalidade superior (Guerreiro Ramos, 1983, 1981; Offe, 1984), uma racionalidade inserta e regulada, pensada no contexto global da governança. 


\section{NOTAS}

${ }^{1}$ Esta denominação de problemas organizacionais está empregada neste tópico de forma restrita, na medida em que não se coloca em uma perspectiva totalizante, como indicaria a trajetória da teoria das organizações, segundo a qual se deveria incluir sua dimensão política, objeto do próximo tópico. Estarei referindo-me aos problemas organizacionais como relativos aos atributos (técnicos, segundo Weber) do modelo de gestão, que implicam certas formas de organização e operação, descritas, por exemplo, no tipo ideal weberiano. Por esta razão, referir-me-ei à organizacional (em negrito). Devo esta observação à Prof. Tânia Fischer.

${ }^{2}$ A noção de governança aqui se emprega no sentido sugerido por Melo (1996), conforme elaborado por Hollingsworth, Schmitter e Streeck (1993): "totalidade de arranjos institucionais incluindo regras e agentes que assegurem o cumprimento dessas regras- que coordenam e regulam transações dentro e fora dos limites de um sistema econômico".

\section{ReferênCias BiblogrRáficAs}

ABERBACH, J.;

PUTNAM, R.;

ROCKMAN, B. A.

Bureucrats and politicians in western democracies. Cambridge : Harvard University Press, 1981.

BENDIX, R.

Max Weber : um perfil intelectual. Brasília : Universidade de Brasília, 1986.

BENNIS, W.

Beyond bureaucracy. New York : McGraw-Hill, 1973.

BERTERO, C. O.

Tipologias e teoria organizacional. ERA, v. 21, n. 1, p. 31-38, jan./ mar. 1981.

BLAU, P.;

SCOTT, W. R.

Organizações formais : uma abordagem comparativa. São Paulo : Atlas, 1970.
BRESSER PEREIRA, L. C.; PRESTES MOTTA, F. C.

Introdução à organização burocrática. São Paulo : Brasiliense, 1980.

CAIDEN, G.

Excessive bureucratization : the Jcurve theory of bureucracy and Max Weber through the looking glass. In: FARAZMAND, A. (Org.). Handbook of bureaucracy. New York : Marcel Dekker, 1994.

CROZIER, M.

O fenômeno burocrático. Brasília : Universidade de Brasília, 1979.

DRAIBE, S.

As políticas sociais e o neoliberalismo. Revista USP, $n$. 17, p. 86-101, 1993. 
DRAIBE, S.;

HENRIQUE, W.

'Welfare state', crise e gestão da crise: um balanço da literaura internacional. Revista Brasileira de Ciências Sociais, n. 6, p. 53-78, 1994.

EISENSTADT, S. N.

Burocratização e desburocratização. In: CAMPOS, E. (Org.). Sociologia da burocracia. Rio de janeiro : Zahar, 1978.

EVANS, P.

Predatory, developmental, and other apparatuses : a comparative political economy perspective on the third world state. Sociological Forum, v. 4, n. 4, 1989.

FAORO, R.

Os donos do poder. Porto Alegre : Globo, 1994.

FERNANDES, R. C.

Privado, porém público : o terceiro setor na America Latina. Rio de Janeiro : Relume-Dumará, 1994.

GOULDNER, A.

Metaphysical pathos and the theory of bureaucracy. In: COSER, L.; BERNARD, R. Sociological theory - a book of readings. New York : McMillan, 1964.

Patterns of industrial bureaucracy. London: Routledge \& Kegan Paul, 1954.

GUERREIRO RAMOS, A.

A nova ciência das organizações : uma reconceituação da riqueza das nações. Rio de Janeiro : Fundação Getúlio Vargas, 1981.

Administração e contexto brasileiro. Rio de Janeiro : Fundação Getúlio Vargas, 1983.
KAST, F. E.;

ROSENWEIG, J. E.

Organizations management : a systems mastems approach. New York : McGraw Hill, 1970.

LINDBLOM, C. E.

$O$ processo de decisão política. Brasília : Universidade de Brasília, 1980.

MANHEIM, K.

Ideología y utopia. México : Fondo de Cultura Económica, 1949.

MARCH, J.;

SIMON, H. A.

Teoria das organizações. Rio de Janeiro : FGV, 1967.

MELO, M. A.

Governance e reforma do estado : $\mathrm{o}$ paradigma agente $\mathrm{x}$ principal. RSP, v. 120, n. 1, jan./abr. 1996.

MENDES, L. C. A.

Para onde vão as ONGs? De assessorias informais de apoio a organizações profissionais estruturadas. Brasília, 1997. Dissertação (Mestrado em Administração) - Departamento de Administração, Universidade de Brasília.

MERTON, R. K.

Social theory and social structure. New York : Free Press, 1959.

MICHELS, R.

Political parties. New York : Free Press, 1949.

MISES, L. V.

Bureaucracy. New Haven : Yale University Press, 1944. 
MOSHER, F.

The public service in the temporary society. In: DWIGHT, W. Public administration in a time of turbulence. Scranton : Chandler Publishers, 1971.

OFFE, C.

Problemas estruturais do estado capitalista. Rio de Janeiro : Tempo Brasileiro, 1984.

PARSONS, T.

The structure of social action. 1937.

PRZEWORSKY, A.

Estado e economia no capitalismo. Rio de Janeiro : RelumeDumará, 1995.

On the design of the state : a principal-agent perspective. Brasília, 1996. (mimeo).

RIBEIRO, S. M. R.

Perspectivas da dinâmica institucional : a emergência do setor público não estatal. Brasília, 1997; Dissertação (Mestrado em Sociologia) - Departamento de Sociologia, Universidade de Brasília.

SELZNICK, P.

An approach to a theory of bureaucracy. In: COSER, L.; ROSENBERG, B. Sociological theory. New York : McMillan, 1964.

TOFFLER, A.

Rumo à civilização da terceira onda. Diálogo, v. 14, n. 22, 1980.

WEBER, $\mathrm{M}$.

Economy and society - an outline of interpretative sociology. Berkeley: University of California Press, 1978.

WRONG, D.

Max Weber. Makers of modern social sciences series. Englewood Cliffs : Prentice Hall, 1970. 